Trends in Ecology \& Evolution

Copyright (C) 2006 Elsevier Ltd. All rights reserved

Shortcut URL to this page: http://www.sciencedirect.com/science/journal/01695347

Hau, B.C.H., Dudgeon, D. and Corlett, R.T. 2005. Beyond Singapore: Hong Kong and Asian

Biodiversity. Trends in Ecology and Evolution 20(6):281-282.

doi:10.1016/j.tree.2005.04.002

\title{
Beyond Singapore: Hong Kong and Asian biodiversity
}

\section{Billy C.H. Hau, David Dudgeon and Richard T. Corlett}

Department of Ecology \& Biodiversity, The University of Hong Kong, Pokfulam Road, Hong Kong

Corresponding author: Hau, B.C.H. (chhau@hku.hk).

At first sight, Hong Kong confirms the worst fears of Sodhi et al. in their recent review article in TREE on the impending biodiversity crisis in Southeast Asia [1]. Hong Kong rivals Singapore in economic development and population density, but is well ahead in its transformation from a forested to human-dominated landscape, which began at least 1000 years ago and was largely completed 700 years later [2]. The loss of species from disturbed and isolated forest fragments that is still underway in Singapore [3] is nearing completion in Hong Kong. There are now no endemic primates, dogs, bears, elephants, tapirs, rhinos, cattle or even squirrels; neither are there any pheasants, hornbills or trogons, and only the occasional vagrant woodpecker is seen. Most forest passerines are habitat generalists and all remaining mammals use successional habitats [2]. Although we do not have pre-impact baselines or intact ecosystems in the region for comparison, it is a reasonable assumption that these missing taxa were present when Hong Kong was covered in forest, and that they disappeared as a result of the human impacts described by Sodhi et al. [1]. Hong Kong appears to be a worst-case scenario for tropical Asian biodiversity.

However, Hong Kong also offers some reasons for guarded optimism. First, extinction has slowed or stopped in most taxonomic groups. Over the past century, during which Singapore suffered many documented species losses [3], few have been lost from Hong Kong [2]. Second, the surviving biota of Hong Kong is still diverse. With the exception of bryophytes, in every group for which there are data, the $1100-\mathrm{km}^{2}$ land area of Hong Kong has more species than are found in the $244800 \mathrm{~km}^{2}$ of the UK, indicating that the latitudinal diversity gradient has survived. Although the mammalian and inland bird faunas are impoverished by regional standards, Hong Kong still has a rich fauna of freshwater fishes [4], amphibians and reptiles, including several well-documented endemic species [2]. The diversity of plants and invertebrates might, in part, reflect an invasion of open-habitat taxa after deforestation, but natural nonforest habitats are rare in the region; thus, the pool of such species must have been limited.

The greatest cause for optimism is that the situation is improving. Although high-density urban development has spread over what little flat land there is, the declining rural population, progressive abandonment of agriculture and the control of hill fires have reduced pressures on upland areas. Secondary shrublands and forest now cover a third of Hong Kong, 40\% of the land area has been set aside for conservation, and the hunting of vertebrates has all but ceased [2]. Most strikingly, the diversities of forest birds and butterflies have increased in recent decades, in contrast to their continued decline in Singapore. Most of these new species appear to have spread unaided from elsewhere in the region, although Buddhist releases have augmented the forest avifauna. Urban development to the north of Hong Kong prevents the reinvasion of less mobile taxa, but some species could now be reintroduced.

Is Hong Kong typical of degraded tropical Asian landscapes? Rugged topography has aided the survival of forestdependent plants and invertebrates in protected pockets of woody vegetation, while frequent typhoons might have preadapted the biota to disturbance. Neither characteristic, however, is unusual in the region as a whole. The absence of a poor rural population that depends on wild species to supplement its livelihood is a characteristic shared with Singapore, but is in stark contrast to much of the rest of Southeast Asia; thus neither region is a worst-case scenario. We agree with Sodhi et al. that deforestation in tropical Asia as a whole will have a massive impact on regional biodiversity, but the example of Hong Kong shows that many species can persist in a human-dominated landscape. Crude speciesarea models overestimate extinctions for taxa that can survive in tiny forest fragments or can utilize secondary forests and shrublands. Tidy Singapore might offer few hiding places for wild species outside the nature reserves, but many Southeast Asian landscapes are more similar to rural Hong Kong. Understanding how biodiversity persists in such landscapes might help us to manage them in a way that would enable more wild species to survive this current period of maximum human impact.

References

1 Sodhi, N.S. et al. (2004) Southeast Asian biodiversity: an impending disaster. Trends. Ecol. Evol. 19, 654-660

2 Dudgeon, D. and Corlett, R. (2004) The Ecology and Biodiversity of Hong Kong, Joint Publishing

3 Brook, B.W. et al. (2003) Catastrophic extinctions follow deforestation in Singapore. Nature 424, 420-423

4 Dudgeon, D. (2003) Clinging to the wreckage: unexpected persistence of freshwater biodiversity in a degraded tropical landscape. Aquat. Conserv. Mar. Freshw. Ecosyst. 13, 93-97 